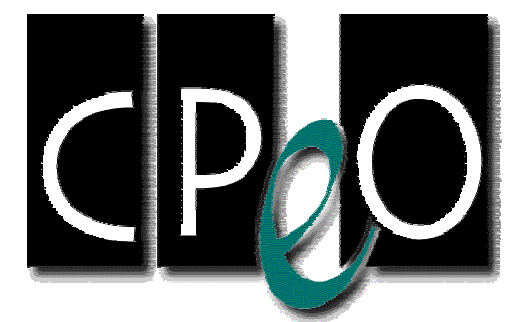

CENTER FOR PUBLIC ENVIRONMENTAL OVERSIGHT

1101 Connecticut Avenue, NW Suite \#1000 Washington, D.C. 20036

Voice: 202-452-8039 Fax: 202-452-8095 EMAlL: cpeo@cpeo.org

\title{
ROUNDTABLE ON LONG-TERM MANAGEMENT \\ IN THE CLEANUP OF CONTAMINATED SITES
}

\author{
Washington, DC
}

June 28, 2002

\section{Summary}

\section{Introduction}

The Center for Public Environmental Oversight (CPEO) convened a roundtable in Washington, DC on June 28, 2002 to discuss innovative approaches to long-term management in the cleanup of contaminated property. Twenty participants attended the meeting, including representatives of federal agencies, local government, state regulatory agencies, environmental organizations, and thinks tanks, as well as private consultants with experience in site remediation and redevelopment.

The purpose of the Roundtable was to stimulate a discussion about what steps should be taken to design a more adaptive approach to the long-term management of contaminated sites. While a number of conferences and meetings about long-term stewardship have been held during the past five years, CPEO was particularly interested in a less explored facet of the problem. Our concern was not just how to ensure the implementation of remedies and institutional controls, but rather how to review and improve their performance over the life of the contamination. As Tara O'Toole, former Assistant Secretary in Office of Environmental Safety and Health, at the U.S. Department of Energy memorably put it: How can we "force inquisitiveness into the system"? Specifically, how might decisions to revise remedies be triggered? What criteria should be used to judge how well remedies are performing? Who should make these decisions? What ethical and social goals should guide these deliberations? Are long-term management responsibilities, for example, best left to current state and federal regulatory agencies and responsible parties such as the Departments of Energy and Defense? Or should they be devolved in part to a trust mechanism, an independent accreditation agency, or some other set of entities? 
The need for a more iterative process to revisit remedy decisions is pressing. As many analysts have pointed out, most Energy Department and Defense Department sites and non-federal Superfund sites will not be cleaned up to unrestricted uses. That is, they will require oversight indefinitely. In addition, at thousands of "minor" sites, such as those being addressed by state voluntary cleanup programs, it will be necessary to manage residual contamination over the long term. The intent of the Roundtable was to consider how existing, proposed, or entirely new institutional arrangements might be shaped to enable and encourage effective long-term management of cleanup programs and land use controls.

\section{Organizing Questions}

To help frame the discussion, CPEO sent participants a list of questions a week before the meeting took place. The questions, it should be noted, were intended more as a point of departure than as a formal charge. Not all of the questions were discussed at the Roundtable; participants raised other weighty issues in the course of discussion. CPEO's original set of questions included the following:

1. How does long-term management compare to long-term stewardship?

2. Do the objectives of long-term management vary by the type of site (nuclear weapons plants, active or closed Defense facilities, private National Priorities List sites, brownfields, decommissioned nuclear power plants, etc.)?

3. In general, is long-term management likely to lead to more or less active remediation? That is, will it increase or decrease the life-cycle costs of cleanup?

4. To what degree do current mechanisms, such as the five-year review, meet the objectives of long-term management? U.S. EPA states that it will not reopen remedy selection decisions unless something calls into question the protectiveness of the remedy.

5. What are the roles of various stakeholder groups (responsible parties, property owners, regulators, local governments, affected communities, stewardship entities, etc.) in implementing and/or funding long-term management activities?

6. How should long-term management be linked to continuing research and development programs?

7. To what degree should initial remedy decisions take into account the legal and/or moral obligation to conduct long-term management during or following the completion of active remediation? 


\section{Current Challenges}

- Defining long-term management

A number of participants noted that there is no commonly understood term that describes responsibilities following the selection of a remedy —or its memorialization in a decision document such as a Record of Decision (ROD). For example, does long-term management start when the remedy is in place? Or should it be integrated earlier into the remedial decision-making process, when institutional controls are identified and other contingencies (e.g. likely changes in site conditions, exposure pathways, migrating contamination, etc.) are taken into account? There was a general consensus that long-term management concerns should be considered before a ROD is signed to avoid foreclosing future options and to recognize the possibility that better technology may become available in the future. For the purposes of the Roundtable, "long-term management" was defined as an adaptive system to make recurring decisions to continue or change remedies that are already in place or will be put in place. In contrast to what many considered a reactive posture of stewardship, long-term management was thought to convey more active responsibility.

- Anticipating pressures to revise remedies

Participants identified a set of factors that could trigger action to revisit remedies.

- Declining protectiveness of engineering controls, as well as remedy failures, such as the limited life of landfill liners.

- The inability of operating remedies, such as pump-and-treat systems, to achieve contaminant concentrations believed to be safe for humane exposure.

- Changes in health standards, such as the revision in arsenic standards. One participant pointed out that new toxicological findings could force remedies to be revised at sites that have been cleaned up to unrestricted use, including some that have even "dropped out of the system".

- The emergence of better technologies. This is particularly likely in the detection and removal of unexploded ordnance.

- Land use and socio-economic changes that might lead to new exposure pathways at or near the sites or demands for groundwater resources not anticipated at the time of the ROD.

\section{- Limitations of five-year reviews}

The preamble to the National Contingency Plan (NCP) states that EPA, in conducting five-year reviews, will not reopen remedy selection decisions unless a new or modified requirement calls into question the protectiveness of the remedy. These new conditions refer to changes in exposure pathways, changes in chemical toxicity, changes in standards, implementation of institutional controls, and expected progress towards meeting remedial action objectives. Despite the provisions of the NCP, which would appear to support long-term management efforts, as well as recent guidance EPA has issued for five-year reviews, Roundtable participants identified a number of problems with the implementation of five-year reviews. These shortcomings fell in two categories: functional and institutional. 


\section{Functional limitations}

Participants noted that the recent Resources for the Future (RFF) report, Superfund's Future: What Will It Cost (2001) was highly critical of EPA's use of five-year reviews. Having examined 151 five-year reviews EPA completed in 1999 and in the first half of 2000, RFF researchers found that EPA determined remedies were protective of human health and the environment even when remedies were not fully in place, functioning as intended, or likely to achieve remedial objectives in the time period anticipated in the ROD. At seven sites where remedies were found not be protective, the report noted that, contrary to five-year review guidance, EPA did not consistently set milestones to achieve protectiveness or specify the party responsible for carrying out recommendations. Other participants noted that five-year reviews are intended to validate protectiveness, to provide only a snapshot of the remedial system in place. They are not used, as it was suggested they should be, to evaluate opportunities to improve the performance of remedies or to lower operation and maintenance costs. Some participants believed that a period of five years between site inspections is too long, unlikely to encourage continuous performance improvement. Many participants thought additional inspections are necessary and opted for annual or biannual reviews.

\section{Institutional impediments}

Attempts to reopen remedy decisions encounter a formidable pair of institutional obstacles: fragmentation and inertia:

\section{Fragmentation}

While the NCP enumerates the conditions for revisiting remedies (see above), it was noted that U.S. EPA has different offices and people working in each area (e.g., cleanup standards, remedy failure, institutional controls, operation and maintenance) and the linkages among these groups are weak. Not only does this arrangement limit the ability of the agency to determine when remedies should be revisited, but also, as a few participants pointed out, the agency is less able to maintain the institutional knowledge that led to the ROD at each site, a resource that could be used to revisit cleanup decisions. Other participants asked if EPA five-year reviews should be subject to independent review and if so, who should "watch the watchers."

\section{Inertia}

Participants also considered the lack of incentives to encourage responsible parties (RPs) to reconsider cleanup decisions based on the ROD. The ROD, it was argued, should not be seen merely as a decision document, but as a mixture of science, art, and political compromise. Revising the ROD would reopen delicate negotiations, so understandably it is likely to be resisted. In the private sector, how does one convince an RP to spend money to apply new technology at a site when the remedy is in place and a review occurs every five years? What incentives or information about technological approaches might make an RP party act? How does one take into account life cycle costs and the social costs of new 
technologies? How does one assign a discount rate-for long-term cost comparisons - that encourages innovation? Moreover, as one participant put it, what interest do hired consultants have to revise remedies when they have "annuities" in long-lasting pump-and-treat systems?

- Collecting and Managing Information

In the course of the Roundtable, it became clear that LTM would involve not only federal and state governments, but a range of other parties including: local government (planning, zoning, redevelopment), land management and environmental organizations, science and technical associations (e.g. ASTM), tribes, RPs, title companies, insurance companies, lending institutions, research and development firms and academic institutions, property managers, historical societies, libraries, and "miss utility" services. This diversity, it was noted, can confound efforts to share existing information and to track the performance of remedies over time. To create an effective tracking system, a core set of data would need to be defined, collected and updated; different data elements currently in use would have to be harmonized across different agencies and levels of government; and long-term funding for such efforts would need to be forthcoming. However, it was noted that, perhaps as a first step, EPA and other federal agencies are considering a "Federal-Wide Data Standard" for an institutional control tracking system. Furthermore, at the local level the International City-County Management Association (ICMA) has developed a new website devoted to land use controls at www.lucs.org. Also, Navy representatives described its Land Use Control Information System, for closure installations. This is accessible at http://navymcbraclucis.org/, but not all installation data has been entered into the system yet.

\section{- Institutional arrangements}

It was generally agreed that the current approach to LTM cannot adequately address the nature of the problem. LTM requires long time commitments, a systematic and coordinated decision strategy based upon adaptive management principles, and the durability that comes with dedicated funding and political support. And yet, it was noted that LTM is hampered because of shifting and conflicting mission goals between agencies and among different levels of government, scientific uncertainty about the health and environment effects associated with hazards as these sites, funding constraints, steep program costs, unclear role responsibilities, and popular mistrust of stewardship due to the legacy of mismanagement at the Departments of Defense and Energy. 


\section{New Institutional Approaches to Long-Term Management}

In the course of discussion, a consensus emerged that there could be no "one size fits all" approach to long-term management, given the extraordinarily long time frame for which many sites will have to be monitored and the range of sites that require periodic review.

Participants explored various institutional approaches to LTM including the creation of an entity to "accredit" institutions that directly provide long-term stewardship or management services.

Participants discussed what sort of private organization, if any, could perform the multiple tasks for LTM. These include: obtaining funds and resources to support LTM requirements; tracking site conditions and the effectiveness of institutional controls; inspecting sites and assessing the performance of remedies; and devising new decision documents that could measure performance periodically against criteria such as "best available technology."

Participants considered whether the non-profit Guardian Trust, perhaps the best known of such entities, could fulfill these functions effectively. The Guardian Trust, a new organization established for this purpose, proposes to take on post-remediation obligations resulting from riskbased cleanups where institutional control or engineering barriers must be maintained as part of a remedy. It has been supported by U.S. EPA and the state of Pennsylvania. The trust would charge RPs - private as well as governmental — an up-front fee, acquire an interest in the property (e.g., an easement) from the RP to enforce institutional controls, and then assume responsibilities for a range of post-remedial services including tracking land use records, site inspections, and the operation of engineering controls such as pump-and-treat systems. The Guardian Trust has not yet been implemented - in fact, it has not yet published details of its plans_-so some participants expressed a "wait and see" attitude.

In principle many participants thought that such a trust mechanism could address many limitations of the current approach to long-term management. A trust could unify a number of functions that are now carried out by different levels of government. Assuming the trust could attract an adequate number of sites, it could create a large enough risk pool to be financially stable. However participants were concerned that such an arrangement might not spur optimal remedies, and that it might be a hard sell politically. Moreover, there was some concern that to remain financially viable the Trust would have to predict accurately future operation and maintenance costs and select an appropriate discount rate to calculate its long-term investment.

The Guardian Trust is but one model for a long-term management entity. Other organizations are being formed for similar purposes, while existing agencies are developing stewardship functions. In the belief that long-term management is a massive, diverse challenge, some of the participants suggested the delineation of classes of LTM agencies. Some might simply serve as recordkeeping services; some might conduct active periodic monitoring; others might actually enforce long-term agreements; while still other full-service entities might attempt to assume all of the obligations of responsible parties, including the revision of remedies. 
No matter what type of LTM institution is called upon to support management at a site, parties at contaminated sites today have no credible, independent mechanism of knowing that such an entity can do the job. For this reason, one participant suggested the formation of an accreditation agency, patterned after the Joint Commission on Accreditation of Healthcare Organizations (JCAHO), to devise performance measures to assess the effectiveness of long-term management entities. Such an agency could devise different criteria for each class of organization. The JCAHO system, in use for some 50 years, scores hospitals according to 48 separate activities, including staffing levels and compliance with codes. JCAHO calculates a weighted overall score and makes a final decision to accredit. Inspections are conducted every three years. Participation is voluntary; paid for by the hospital; and the process is intended to improve performance. Hospitals work hard to raise their accreditation scores, in part because of their value in marketing.

It should be emphasized, however, that JCAHO accreditation runs in tandem with state licensing efforts. This relationship was not discussed at the Roundtable. Hospitals are licensed by the states when they meet regulatory requirements and, unlike JCAHO's accreditation scheme, states can and will assign fines to hospitals as well as suspend their licenses to operate if they fail to meet minimum standards.

State licensing in effect takes a command and control approach to hospital operations. By contrast, JACHO relies on market pressures to spur improved performance. Clearly the analogy with LTM is somewhat forced, but the value of JCAHO for the purposes of the Roundtable lies in its well-recognized set of performance measures, an orientation toward continuous improvement, an approach based on education and consultation, and the public's trust in the accreditation scheme.

However, one perhaps should remain somewhat cautious about developing accreditation schemes for LTM organizations. For example, JCAHO's criteria are based on a consensus of what seems to work in hospitals, but there may be important features of hospital organization or culture that have been left out, a point borne out by a recent study by two Michigan professors, which suggests hospital accreditation is a poor predictor of the quality of patient outcomes. (See Griffith et al. "Structural versus Outcomes Measures in Hospitals" http://www.aspenpublishers.com) The lesson, perhaps, is that all stakeholder groups should participate in the creation of LTM accreditation or licensing schemes, whether they are implemented by government agencies or independent entities.

\section{Next steps}

Participants in the Roundtable agreed that the issues raised that day should be followed up. Some felt that pilot studies would be a good way to further the ideas put forward. There seemed to be agreement on the need to educate the public, Congress, and various stakeholder groups about the challenges on long-term management.

CPEO hopes to pursue this topic in cooperation with other organizations represented at the Roundtable. Our initial thoughts are to focus on three approaches: 
1. To continue to make the case, at individual sites as well as national policy discussions, that long-term management starts at the beginning of the cleanup process. Remedial alternatives that leave contamination in place (at levels not allowing for unrestricted use or unlimited exposure) should be evaluated, in detail, against those which do not require long-term management. Long-term costs should not simply be calculated to reach zero after thirty years. Remedies, including both containment and long-term extraction, should include contingency plans should failure occur or even appear imminent. Stewardship and management requirements should be agreed upon in enforceable documents such as Records of Decision.

2. To develop a collaborative research proposal, based upon Roundtable discussions, to define various classes of LTM entities, propose criteria for evaluating individual LTM entities, and devise an accreditation scheme or institutional model for rating LTM organizations. We feel that this approach is superior to simply backing or critiquing LTM institutions as they emerge.

3. To develop a research proposal to consider models for improved public participation in long-term management at contaminated sites. When we took part in the Federal Facilities Environmental Restoration Dialogue Committee, the watchword for community involvement was "early and often." The recognition that contamination may remain in place indefinitely, or that active treatment may stretch over decades, suggests a new paradigm: "early, often, and forever." Yet the opportunities for public involvement decline at sites once remedies are selected, and public stakeholders often move on to other issues, even though they may remain, in the long run, the most informed stakeholders - as the employees of responsible parties and regulatory agencies move to other jobs or retire. CPEO wishes to explore mechanisms for continuing public oversight that is compatible with lower levels of activity, but which maintains the opportunity to regenerate interest should remedial decisions need to be revisited down the road.

Though there are currently differences among government agencies about how to document and enforce long-term management requirements, we believe that all parties have a common interest in promoting the research activities explained in points 2 and 3 above.

The following people participated in the June 28, 2002 CPEO Roundtable on Long-Term Management in the Cleanup of Contaminated Sites. Listing should not be construed as implying that either the individuals or their organizations agree with the findings or suggestions in the summary.

Cal Baier-Anderson, University of Maryland-Baltimore

Michael Bellot, U.S. EPA

Zafer Demir, Lawrence Livermore National Laboratory

Deeohn Ferris, Global Environmental Resources Inc.

Bob Hersh, CPEO

Aimée Houghton, CPEO

Mario Ierardi, Air Force, Base Conversion Agency

Seth Kirshenberg, Energy Communities Alliance 
Murray Newton, U.S. EPA

Stan Phillippe, California Department of Toxic Substances Control

Kate Probst, Resources for the Future

Joe Schilling, International City/County Management Association

Tom Schruben

Lenny Siegel, CPEO

Peter Strauss, PM Strauss \& Associates

Merv Tano, International Institute For Indigenous Resource Management

Bill Walsh, Pepper, Hamilton,LLP

Paul Yaroschak, Office of the Assistant Secretary of Navy (Installations

\& Environment)

Doug Zillmer, Office of the Assistant Secretary of Navy (Installations

\& Environment) 